\title{
The Research Status of Neurological Surgery Residents; A Survey of Iranian Residency Programs
}

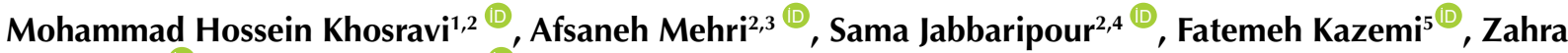 \\ Khosravi $^{2,6} \mathbb{D}^{\mathbb{D}}$, Sayedali Ahmadi ${ }^{*} \mathbb{C}^{\mathbb{C}}$
}

${ }^{1}$ Functional Neurosurgery Research Center, Shohada Tajrish Comprehensive Neurosurgical Center of Excellence, Shahid Beheshti University of Medical Sciences, Tehran, Iran ${ }^{2}$ Department of Research, Arka Education and Clinical Research Consultants, Tehran, Iran ${ }^{3}$ Faculty of Pharmacy, Tehran Medical Sciences, Islamic Azad University, Tehran, Iran ${ }^{4}$ School of Medicine, Tehran University of Medical Sciences, Tehran, Iran ${ }^{5}$ Student Research Committee, Qazvin University of Medical Sciences, Qazvin, Iran ${ }^{6}$ Student Research Committee, Faculty of Medicine, Semnan University of Medical Sciences, Semnan, Iran ${ }^{7}$ Department of Neurosurgery, Rasool Akram Hospital, Iran University of Medical Sciences, Tehran, Iran

\begin{abstract}
Background: Research activities promote the appreciation for evidence-based medicine (EBM), quality patient care and clinical competence of resident physicians. We decided to investigate the research background of Iranian neurological surgery residents and their attitude toward research through a survey.

Methods: This cross-sectional study was done on Iranian neurological surgery resident physicians between February and April 2020. We provided an online survey, including 13 questions, using Google form and then sent the link to survey via WhatsApp application. Following the first post, two more reminders were sent to the groups after 2 and 4 weeks.

Results: Responses were received from 89 respondents from which about $88 \%$ used to spend two hours or less per week for research. Almost equal numbers of resident physicians chose academic position $(n=43)$ or private practice $(n=39)$ as their future job. Only seven respondents stated immigration for assumed future job position. Clinical research $(47 \%)$ was the most frequent type of research done by participants and clinical research education (43.2\%) during medical school was the most common way of obtaining research experience. Agreement with doing research during residency program $(45.6 \%)$ was more than disagreement $(22.4 \%)$ and neutral attitude $(32 \%)$.

Conclusion: There is a low tendency among Iranian neurological surgery residents for conducting research projects during their programs. Lack of a proper research curriculum, heavy clinical duties and consequent shortage of time as well as insufficient encouraging points, are the main reasons. Designing a research plan for residency programs may successfully increase the research involvement rate.
\end{abstract}

Keywords: Medical residency; Research; Curriculum; Survey; Neurological surgery.
*Correspondence to Sayedali Ahmadi, M.D. Address: Department of Neurosurgery, Rasool Akram Hospital, Tehran, Iran Phone number: $+989126111701$

Fax number: 02182141787 Email: ahmadi.as@iums.ac.ir

Published online 30 October 2021

Citation: Khosravi MH, Mehri A, Jabbaripour S, Kazemi F, Khosravi Z, Ahmadi SA.The research status of neurological surgery residents: a survey of iranian residency programs. Clin Neurosci J. 2021;8(4):193-197. doi:10.34172/icnj.2021.38.

\section{Introduction}

Research activities play an integral and important role in medical training. ${ }^{1,2}$ According to the Accreditation Council for Graduate Medical Education (ACGME), program requirements for graduate medical education in internal medicine, scientific knowledge, the scientific method of problem-solving, evidence-based decisionmaking and a commitment to lifelong learning are inherent to the discipline. ${ }^{1}$

Research enhances self- and lifelong learning skills, intellectual curiosity, and critical thinking which facilitate evidence-based decision-making. ${ }^{1,34}$ Research promotes the appreciation for evidence-based medicine (EBM), quality patient care and clinical competence of resident physicians. ${ }^{1}$ Resident physicians take benefits from research training by learning how to present clinical issues, evaluate literature, use research skills and work under supervision of mentors. ${ }^{4}$ It improves analytic reading skills which can prepare graduates for different types of research roles in the academia and community. ${ }^{3}$

(C) 2021 The Author(s). This is an open access article distributed under the terms of the Creative Commons Attribution License (http:// creativecommons.org/licenses/by/4.0/), which permits unrestricted use, distribution, and reproduction in any medium, provided the original work is properly cited. 
It is also a prerequisite for fellowship application and helps with career development and encourages resident physicians to pursue clinician-scientist career for which the demand has been recently declined. ${ }^{1,4}$

Despite all the above-mentioned advantages, research participation rate remains relatively low among resident physicians. A variety of reasons including shortage of time, lack of infrastructure, mentorship or suitable research curriculum, limited financial support, insufficient motivations and reward, lack of personal interest in research and high loads of clinical duties, have been considered for this issue. , $^{1,3,4}$

Studies on this subject have been conducted in different parts of the world. In 2019 a study was conducted to assess the status of academic training and activity of residents and young urologists in Spain to identify developments and help promote training programs. The results of this study showed that scholarship output and research publication by urology residents was low. ${ }^{5}$

According to the importance and influence of research activities on quality of residency training program and since there is no significant information about this topic in Iran, we decided to investigate the research background of Iranian neurological surgery residents and their attitude toward research activities through a survey.

\section{Material and Methods}

This cross-sectional study was done on Iranian Neurological surgery residents from Tehran and Mashhad, Iran, in Shahid Beheshti and Mashhad Universities of Medical Sciences between February and April 2020. We provided an online survey using Google form (Google LLC, Mountain View, California, United States), and then sent the survey's link via WhatsApp application, in which resident physicians from Shahid Beheshti and Mashhad Universities of Medical Sciences have groups. As a result, information was retrieved from Imam Khomeini and Sina (Tehran), Rasool-e-Akram and Firozgar (Iran), Loghman-e-Hakim and Shohaday-e-Tajrish (Shahid Beheshti) and Ghaem (Mashhad) university hospitals. Following the first post, two more reminders were sent to the groups after two and four weeks. The survey included 13 questions which are listed in Table 1. Answering this survey was optional and no one was obligated to participate the study.

Data were analyzed using IBM SPSS Statistics for Windows (version 21, IBM Corp, Armonk, NY). Quantitative variables reported as mean (SD) and percent. Qualitative variables were expressed by number and percent.

\section{Results}

Responses were received from 89 respondents, who were in first post-graduate year (PGY-1, 7.46\%), PGY-2 (29.34\%), PGY-3 (12.54\%), PGY-4 (33.57\%) and PGY-5
Table 1. Survey Questions and Available Choosing Options

\begin{tabular}{|c|c|}
\hline 1. What is your level of education? & PGy-1,2,3,4,5 \\
\hline $\begin{array}{l}\text { 2. What is your most favorite } \\
\text { fellowship program? }\end{array}$ & $\begin{array}{l}\text { Spine, pediatric, } \\
\text { endovascular, peripheral } \\
\text { nerves, functional, skull } \\
\text { base, vascular surgery }\end{array}$ \\
\hline $\begin{array}{l}\text { 3. Which environment are you } \\
\text { interested in for your future career? }\end{array}$ & $\begin{array}{l}\text { Academic, private practice, } \\
\text { immigration }\end{array}$ \\
\hline $\begin{array}{l}\text { 4. What has been the background } \\
\text { of your research activity? }\end{array}$ & $\begin{array}{l}\text { Case report, case series, } \\
\text { lab. research, clinical } \\
\text { research, all of them }\end{array}$ \\
\hline $\begin{array}{l}\text { 5. How have you gained your past } \\
\text { research experience? }\end{array}$ & $\begin{array}{l}\text { Basic science level, clinical } \\
\text { research in medical school, } \\
\text { workshops in medical } \\
\text { school, W/O academic } \\
\text { education }\end{array}$ \\
\hline $\begin{array}{l}\text { 6. How did you present your past } \\
\text { research results? }\end{array}$ & $\begin{array}{l}\text { Published article, Oral } \\
\text { presentation, Poster } \\
\text { presentation }\end{array}$ \\
\hline $\begin{array}{l}\text { 7. How many hours a week do you } \\
\text { do research? }\end{array}$ & 0 to 10 (free to choose) \\
\hline $\begin{array}{l}\text { 8. Have you ever made money } \\
\text { from doing research? }\end{array}$ & Yes, No \\
\hline $\begin{array}{l}\text { 9. At which level were the results } \\
\text { of your research presented? }\end{array}$ & National, International \\
\hline $\begin{array}{l}\text { 10. What is your opinion about } \\
\text { doing research activities during } \\
\text { your residency? }\end{array}$ & $\begin{array}{l}\text { Agree, do not mind } \\
\text { (neutral), disagree }\end{array}$ \\
\hline
\end{tabular}
your residency?

11. What can be a good incentive for research activities?

\section{Promotion grade,} employment at universities, income, obligation, providing conditions for taking part in congresses Obligation, additional time, defining great

12. What is your suggested solution for increasing your research activities during residency? budgets, travel grants or complementary courses, assigning a research assistant

Shortage of time, financial issues, lack of proper research topics, not enough motivation, lack of colleagues who are expert in statistics, lack of support from faculty or ward

(17.09\%), neurological surgery resident physicians. Some questions were not answered by some participants which became our missing data. All percentages mentioned in following text are valid by excluding the absent data.

For spine, skull base and vascular surgery fellowships, 25 (28.8\%), 23 (25.84\%) and 20 (22.47\%) respondents were interested to take part, respectively. Endovascular, functional and pediatrics were favorite fellowships of $8(8.98 \%), 8(8.98 \%)$ and $4(4.49 \%)$ participants, respectively. The least favorite fellowship was peripheral nerves surgery, chosen by only 2 residents.

Almost equal numbers of resident physicians chose academic position $(\mathrm{n}=43,52.4 \%)$ or private practice $(\mathrm{n}=39,47.6 \%)$ as their future job. Only seven respondents 
stated immigration for assumed future job position. We found that $88.5 \%$ of the participants spend two hours or less per week for research activities (Figure 1). Shortage of time seemed to be a lot more disturbing than other limiting factors. Lack of proper research topic was chosen by only six residents (Table 2). Clinical research was the most frequent type of research done by participants and clinical research education during medical school was the most common way of obtaining research experience (Table 3).

Research-related income as well as setting and form of presentation, were other evaluated factors. Only six participants had experience of research-related income. An almost equal number of participants had performed their presentations at only national $(\mathrm{n}=28,36.7 \%)$ or international $(\mathrm{N}=26,34.3 \%)$ meetings. Remaining participants ( $\mathrm{n}=21,29 \%)$, excluding 14 non-responders to this question, had experience with both national and international presentations.

Most usual way of presenting researches $(\mathrm{n}=38,51.4 \%)$ were articles. Other types of presentations included oral $(n=5,6.5 \%)$ and poster presentation $(n=2,3.4 \%)$. The rest of participants $(n=30,38.7 \%)$ had performed all three kinds of presentations.

Agreement with doing research during residency program $(n=37,45.6 \%)$ was approximately two times more than disagreement $(n=18,22.4 \%)$, considering 25 (32\%) respondents with neutral attitude.

Considering solutions for increasing research activities among residents, providing additional time and great budgets were chosen more than other options, almost equally (Table 4). The most interesting encouragement for residents was income. Obligation and hiring in universities were not apparently good enough in respondents' point of view (Figure 2).

\section{Discussion}

Findings suggest that, more than half of the responders agreed with research activities during the residency program. We found that immigration and continuing medical practice in foreign countries, is not the plausible

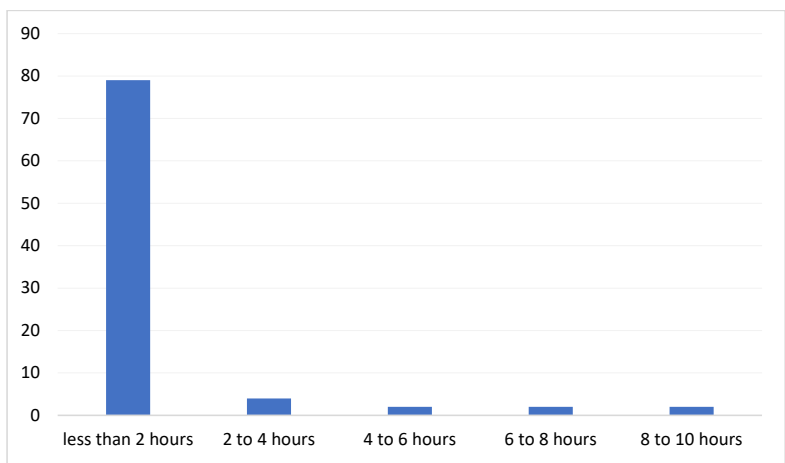

Figure 1. Distribution of Time Dedicated for Research Activities Per Week.
Table 2. Limiting factors for Research activities $\left(\mathrm{N}_{\text {total }}=89\right)$

\begin{tabular}{lcc}
\hline & N & (\%) \\
\hline Time shortage & 43 & $(48.3)$ \\
Not enough motivation & 18 & $(20.2)$ \\
Lack of colleagues expert in statistics & 12 & $(13.6)$ \\
Lack of support from faculty or ward & 8 & $(9)$ \\
Financial issues & 6 & $(6.7)$ \\
Lack of proper research topic & 2 & $(2.2)$ \\
\hline
\end{tabular}

Table 3. Research Experience of Study Participants

\begin{tabular}{lcc}
\hline Variables & N & $(\%)$ \\
\hline Type of research $(\mathrm{N}=81)$ & 38 & $(47)$ \\
$\quad$ Clinical research & 17 & $(21)$ \\
Case report & 10 & $(12.3)$ \\
Case series & 5 & $(6.1)$ \\
Lab research & 11 & $(13.6)$ \\
All of above & & \\
Method of research experience $(\mathrm{N}=81)$ & 35 & $(43.2)$ \\
Clinical research during medical school & 26 & $(32.1)$ \\
Workshops during medical school & 12 & $(14.8)$ \\
W/O academic education & 8 & $(9.9)$ \\
Basic science & & \\
\hline
\end{tabular}

Table 4. Solutions for Increasing Research Activities Among Residents ( $\mathrm{N}=89$ )

\begin{tabular}{lcc}
\hline & N & (\%) \\
\hline Defining great budgets & 49 & $(55)$ \\
Additional time & 20 & $(22.6)$ \\
Free travel or complementary courses & 10 & $(11.2)$ \\
Definition of colleague & 4 & $(4.5)$ \\
Obligation & 4 & $(4.5)$ \\
All except obligation & 2 & $(2.2)$ \\
\hline
\end{tabular}

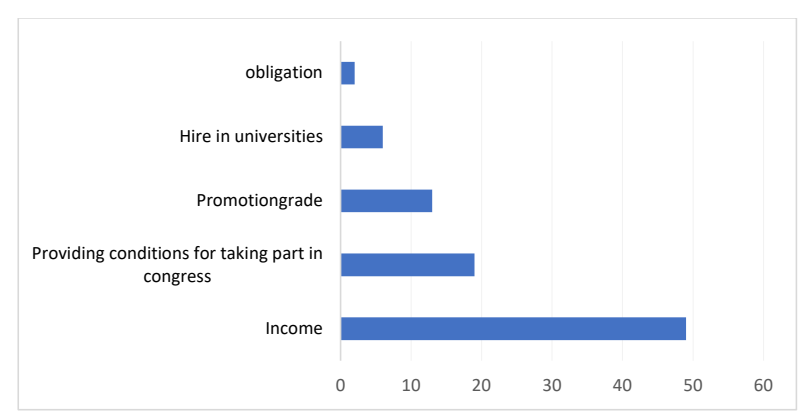

Figure 2. Encouragements for Doing More Research.

choice for Iranian neurological surgery resident physicians. As there are no private residency training programs in Iran, all the residents should sign an official 4-year commitment paper for practicing as governmental physician (in return for the free training), before entering 
the residency program. Based on this commitment, the Iranian Ministry of Health and Medical Education has the right to determine the city and hospital of practice for graduated specialists.

An almost equal proportion of respondents chose private practice and academic position as their favorite future job. Currently, private practice has a little more income guarantee for surgeons in Iran; however, finding a position for private practice is really difficult for a young surgeon. On the other hand, gaining an academic position is not that unreachable if you have hands on research and good national board exam points. Working as a faculty member involves more research and educational activities; however, it is not usually accompanied by adequate income as they have less chance for dual practice compared with non-faculty surgeons. ${ }^{6}$

We found that nearly $90 \%$ of the respondents dedicated less than two hours a week to research among which a huge proportion had no research activities. We found that shortage of time and lack of motivation was the cause in about $70 \%$ of the responses. PGY-1 and PGY-2 resident physicians had at least 15 night shifts in a month beside their heavy daily clinical duties which would surely not spare anytime for thinking of research despite facing various interesting cases and research topics. Currently, no specific points or facilities are provided for resident researchers that seems to be the main reason for lack of motivation. The participants' most commonly chosen solutions for increasing research activities, were "assigning more budget for research" and "additional time". Because of the notably low monthly salary of resident physicians in Iran compared with their long working hours, ${ }^{7}$ it seems that financial assistance will be a good promoter of research activities. On the other hand, residents interested in research should have lighter clinical duties so that they can pursue their interest.

Findings of a study marked that some strategies such as improving research methodology training, an appropriate structured-protected time for scholarship, increasing organizational financial support, and devoting a scholarly activity award system could enhance research output in international medical centers. ${ }^{8}$ Another study demonstrated that some interventions such as protected time and research curricula are effective in increasing participation in research activities or publications. Also there was a need for more structured programs and a clear definition of residents' research success. ${ }^{9}$

In 2019, a nationwide study was performed in Japan to examine research activities among pediatric residents. This study indicated that most pediatric residents' research activities were limited to presentations at scientific conferences and few residents had published their research. There was also a considerable variation in research activity according to the type of institution. ${ }^{10}$

In early 2020 a study was organized to investigate the Italian's neurosurgical residents' perceptions and experiences in research activities through a national survey with a response rate of $41.5 \%{ }^{11}$ The most prevalently reported encouraging factors for research activities were interaction with peers, mentorship and conference exposure, respectively. This is in line with the results of our study where travel or conference grants was the third most chosen encouraging factor by the residents. Also, call schedule was a limiting factor in more than $60 \%$ of the participants which is consistent with our study.

Lack of a proper research schedule or curriculum was one of the most important and least considered issues on residency research activities, no matter in which country the program was. ${ }^{12-14}$ Results of another study reported that the research curriculum was associated with long-term improvement of research products and more collaboration of residents and faculty. ${ }^{15}$ Authorities believe that new strategies may be embedded in educational programs to increase residents' interest and their participation in research. ${ }^{1}$ Wolfe and colleagues demonstrated an increase in research enterprises among residents and faculty at an extensive level of individuals in medical education by developing a strategic research plan. ${ }^{16}$

The present study had some limitations. Although electronic surveys play a notable role in the current pandemic situation, having no opportunity to talk with respondents and delivering paper surveys, may have affected the responses. Moreover, this study has been conducted in the COVID-19 pandemic era, which has undeniable negative effects on research and educational activities which may have decreased the rate of participation. In this survey we received answers from nearly $70 \%$ of possible respondents which is a relatively high rate of participation. Heavy clinical duties and lack of time as well as giving a very low priority to research activities, which is common among Iranian medical students and resident physicians, may be influential. ${ }^{7}$

\section{Conclusion}

Lack of a proper research curriculum, heavy clinical duties and consequent shortage of time as well as insufficient encouraging points, are the main reasons for low tendency toward research activities among Iranian neurosurgery residents. In addition, we realized that designing a research plan for residency programs may successfully increase the research involvement rate.

\section{Conflict of Interest Disclosures}

The authors declare that they have no conflict of interests.

\section{Ethical Statement}

The present study was conducted in accordance with the Helsinki Declaration. All the personal data remained anonymous. 
Funding

There is no funding or supporting sources for the present manuscript.

\section{Acknowledgements}

Authors would like to thank all the resident physicians who responded to the questionnaire.

\section{References}

1. Chan JY, Narasimhalu K, Goh O, Xin X, Wong TY, Thumboo J, et al. Resident research: why some do and others don't. Singapore Med J. 2017;58(4):212-7. doi: 10.11622/smedj.2016059.

2. Ercan-Fang NG, Rockey DC, Dine CJ, Chaudhry S, Arayssi T. Resident research experiences in internal medicine residency programs-a nationwide survey. Am J Med. 2017;130(12):1470-6.e3. doi: 10.1016/j. amjmed.2017.08.033.

3. Alguire PC, Anderson WA, Albrecht RR, Poland GA. Resident research in internal medicine training programs. Ann Intern Med. 1996;124(3):321-8. doi: 10.7326/00034819-124-3-199602010-00007.

4. Jaroonvanichkul V, Deerojanawong J. Residents' obstacles and attitudes toward research during residency training. J Med Assoc Thai. 2016;99(2):239-44.

5. Rodríguez Socarrás M, Ciappara M, García Sanz M, Pesquera L, Carrión DM, Tortolero L, et al. Current status of young urologists and residents' activity and academic training in Spain. National survey results. Actas Urol Esp (Engl Ed). 2019;43(4):169-75. doi: 10.1016/j. acuro.2018.11.002.

6. Bayat M, Khalilnejad R, Akbari-Sari A, Harirchi I, Salehi Zalani G, Mirbahaeddin SE, et al. Factors associated with dual practice in surgery specialists: application of multilevel analysis on national registry data. Iran J Public Health. 2019;48(5):882-92.

7. MOHME. Regulations of Resident Physician Training Programs. https://cgme.behdasht.gov.ir/uploads/264/doc/ Sp_Neurosurgery.pdf. 2018.

8. Nair SC, Ibrahim H, Almarzoqi F, Alkhemeiri A, Sreedharan
J. Addressing research barriers and facilitators in medical residency. J Family Med Prim Care. 2019;8(3):1145-50. doi: 10.4103/jfmpc.jfmpc_38_19.

9. Stevenson MD, Smigielski EM, Naifeh MM, Abramson EL, Todd C, Li ST. Increasing scholarly activity productivity during residency: a systematic review. Acad Med. 2017;92(2):250-66. doi: 10.1097/acm.0000000000001169.

10. Ishiguro A, Nomura O, Michihata N, Kobayashi T, Mori R, Nishiya K, et al. Research during pediatric residency training: a nationwide study in Japan. JMA J. 2019;2(1):2834. doi: 10.31662/jmaj.2018-0007.

11. Zaed I, Menna G, Caccavella VM, Stumpo V, Giordano M, Caimmi E, et al. Italian neurosurgical residents' experience with research activities: a national survey. World Neurosurg. 2020;142:e101-e10. doi: 10.1016/j.wneu.2020.06.105.

12. Oliver JJ, Ross JM, Davis WT, Ng PC, Long B, Weymouth $\mathrm{WL}$, et al. The development of an emergency medicine resident research program in the United States military. Mil Med. 2019;184(11-12):e622-e5. doi: 10.1093/milmed/ usz071.

13. Dahn HM, Best L, Bowes D. Attitudes towards research during residency training: a survey of Canadian radiation oncology residents and program directors. J Cancer Educ. 2020;35(6):1111-8. doi: 10.1007/s13187-019-01565-8.

14. Ercan-Fang NG, Mahmoud MA, Cottrell C, Campbell JP, MacDonald DM, Arayssi T, et al. Best practices in resident research- a national survey of high functioning internal medicine residency programs in resident research in USA. Am J Med Sci. 2021;361(1):23-9. doi: 10.1016/j. amjms.2020.08.004.

15. Harrison LM, Woods RJ, McCarthy MC, Parikh PP. Development and implementation of a sustainable research curriculum for general surgery residents: a foundation for developing a research culture. Am J Surg. 2020;220(1):1058. doi: 10.1016/j.amjsurg.2019.09.028.

16. Wolfe J, Wolfe J, Smith K, Yoho R, Vardaxis V. A strategic plan for increasing scholarly activity among medical students, residents, and faculty. J Am Podiatr Med Assoc. 2018;108(4):292-303. doi: 10.7547/16-014. 